\title{
ENTRE EL MÉTODO Y LA TEORÍA
}

\section{El debate disciplinar por la definición de las autopistas urbanas en Estados Unidos}

\author{
Romina Canna \\ Universitat Politècnica de Catalunya, Barcelona, España. Profesora Asociada en \\ Arquitectura: IE University, Segovia, España \\ Director: Joaquín Sabaté Bel
}

\section{RESUMEN}

A mitad del siglo XX, el futuro de la ciudad americana se debate entre el pragmatismo de un método y la utopía de una teoría. Este artículo explora la validez de los instrumentos disciplinares surgidos entre ingenieros y urbanistas a partir de la construcción del sistema de autopistas interestatales en Estados Unidos, más específicamente, en el seno de la ciudad. Los años comprendidos entre 1956 y 1962 marcan un cambio radical en la forma de la ciudad americana, pero más importante aquí, reafirman las estructuras profesionales tras su construcción. Tres conferencias, Hartford (1957), Sagamore (1958) y Hershey (1962) son el escenario de un feroz debate disciplinar, y un intento del urbanismo por recuperar el territorio perdido, aún cuando los nuevos constructores de la ciudad ya ocupan, cómodamente, sus lugares.

Palabras clave: Autopistas urbanas, ciudades norteamericanas, instrumentos disciplinares. 
ID_INVESTIGACIONES

\section{ABSTRACT}

In the middle of the twentieth century, the American city debated its future between the pragmatism of a method and the utopia of a theory. This article explores the debate over the validity of disciplinary tools that emerged between engineers and urban planners from the construction of the Interstate Highway System in the United States, more specifically, in the heart of the American city. The years between 1956 and 1962 marked a radical change in the shape of the American city, but more importantly, these years would mark the reaffirmation of the professional structures behind its construction. Three conferences, Hartford (1957), Sagamore (1958) and Hershey (1962) would be the stage of a ferocious disciplinary debate, and an attempt by the discipline of urban planning to recover lost territory, even while the new builders of the city were already occupying their places.

Keywords: Urban highways, American cities, disciplinary instruments. 


\section{INTRODUCCION}

En Estados Unidos, el siglo XX tiene dos partes, en la primera se debate, u omite debatir, el futuro de la ciudad. En la segunda, la ciudad americana se construye.

En 1957, las críticas y el escepticismo hacia el recién comenzado sistema interestatal de autopistas, han alcanzado su punto de ebullición. En septiembre de ese año, la Connecticut General Life Insurance Company, organiza la conferencia "The New Highways: Challenge to the Metropolitan Region" como un punto de inflexión para intentar un acercamiento entre quienes construyen las autopistas con meticulosos manuales y quienes las destruyen con lapidarias críticas. La conferencia, primera de una serie de tres que intentaremos explicar aquí, son el escenario de un intento desesperado del urbanismo por formar parte de una empresa, de fuerte impacto territorial y urbano, de la que han quedado excluidos. ¿O autoexcluidos?

Echando la vista atrás, y con el beneficio del espacio que da el tiempo, se hace evidente que las conferencias fueron un campo de batalla de una guerra que llegó demasiado tarde. El territorio ya había sido apropiado. El debate satisfizo al público expectante: escandalosas acusaciones, serias afirmaciones, y apasionadas denuncias inundaron páginas de periódicos, libros y discusiones por años. Sin embargo la maquinaria institucional y profesional detrás de las autopistas había sido ya decidida largo tiempo atrás. Dos factores contribuyeron a ello: por un lado, una especialización profesional gestada y nutrida por décadas ante la vista distraída de otras disciplinas, y por otro, una estructura institucional que se consolidaba a través de demandas específicas, ante el fracaso del urbanismo para involucrarse en una nueva realidad de la ciudad y desarrollar los instrumentos apropiados para ser parte de ella.

\section{HISTORIA URBANA}

¿Existe un origen, un punto de partida, en donde marcar el nacimiento de las autopistas urbanas? Y un poco más allá de su origen, ¿Cuál fue el verdadero proyecto de la autopista urbana? ¿Quienes fueron sus autores? ¿Puede la historia reconstruir un mapa de su génesis?

Difícilmente encontremos en la historia de la ciudad una discusión tan encendida sobre 


\section{ID_INVESTIGACIONES}

un episodio urbano que, paradójicamente, nunca fue concebido para serlo. Las autopistas urbanas son el resultado de la colisión de una construcción consciente, determinada a dar respuesta a unas demandas específicas que guiaran su construcción material, y otra de tipo inconsciente, resultado de una infiltración de episodios ajenos a ella que actuaron como una incubadora accidental. De esta colisión y el contexto histórico en el que las autopistas se originaron surge una estructura institucional y disciplinar precisa que serán decisivos en su formación y consolidación.

\subsection{Inconsciente productivo}

El siglo XX fue escenario de tiempos convulsos en el seno de las ciudades americanas. E rápido crecimiento de población en conjunción con el creciente poder militar y económico produjo una serie de acontecimientos sin precedentes, y las ciudades serían el escenario de su materialización. Tres fenómenos, alimentados de diversos episodios fueron, sin saberlo, las células madre del sistema de autopistas interestatales en sus tramos urbanos.

\subsubsection{Defensa y estrategia}

Los conflictos bélicos internacionales que habían debutado con el principio del siglo suponían el despliegue de un nuevo poderío y agregaban un nuevo e imprescindible componente a la estrategia de la guerra: el movimiento. La guerra no se libraba ya en el campo de batalla, sino en el territorio mismo. Estados Unidos, quien enfrentaba ahora la responsabilidad de ser una de las potencias mundiales en términos económicos y de defensa, debía responder a esos nuevos requerimientos, preparando su ejército y su territorio para la nueva era militar. La estrategia de guerra era ahora una red de infraestructura y la organización del territorio se convertía en un instrumento de defensa.

En 1919, la "Transcontinental Motor Convoy" supuso un "juego de guerra". El objetivo de la expedición era probar la capacidad de movimiento del ejército americano desplazando todo un arsenal a través del continente, uniendo ambas costas, desde Washington hasta San Francisco en medio de una guerra ficticia. La expedición se llevo a cabo sobre la llamada 
"Lincoln Highway"1. Como la guerra que libraban, la autopista era una fantasía que debía trazarse bajo los pasos y de la forma más eficiente y directa posible.

La expedición hizo evidente la ausencia de una red eficiente de vías territoriales. En 1921 el congreso aprueba una ley que impulsa la creación de un sistema de autopistas interestatales con el apoyo federal. La estructura institucional para su construcción era simple, los estados serían los encargados de clasificar y planear las autopistas a través de sus departamentos de caminos dejando al estado federal en manos del Bureau of Public Roads (BPR) la aprobación de las vías seleccionadas y la supervisión de su diseño y construcción.

Luego de la firma de la ley, Thomas MacDonald, entonces director del BPR, realiza un primer trazado del sistema interestatal de autopistas que envía a la cúpula militar para confirmar que la red satisfacía las necesidades estratégicas del ejército para el que estaba siendo creado. Meses más tarde, ya en 1922, el General John Pershing entrega al Bureau la selección de rutas con un detalle de las necesidades estratégicas para cada estado, y para la red como sistema. El mapa, conocido como el Pershing Map es el primer registro de un sistema interestatal y su geometría revela su origen, la conexión entre puntos de valor estratégico y la más directas y practicables rutas de unión entre los mismos.

El sistema de interestatales comenzaba a ser tejido entre la pericia de quienes hacian caminos y podían garantizar su calidad constructiva, a través del BPR y un diseño, basado en las necesidades propias de su usuario original, la defensa territorial. Mientras los últimos era quienes establecían la demanda, los primeros se convertían en los especialistas para su materialización.

En 1935, Adolf Hitler inauguraba el primer tramo desde Frankfurt a Darmstadt de la Reichsautobahn. La red, construida con los más modernos estándares de ingeniería era el más exitoso emprendimiento político, sostenía el prospecto de un imperio por construirse, hacia alardes una modernidad asumida como forma de vida de una nación, y era a su vez el mejor afiche publicitario para el gobierno de Hitler. Sus ingredientes eran ideales y Estados Unidos concurría extasiada a contemplarla para aprender de ella. La Reichsautobahn se convirtió en el modelo a seguir.

${ }^{1}$ La Lincoln Highway es ahora la U.S. 30 y fue creada en 1913 por Carl Fisher, un empresario progresista, con la intención de construir una ruta que vinculara las dos costas. Hasta ese momento las rutas eran líneas rudimentarias de conexión local y con una pobre calidad constructiva. 
En 1938, MacDonald es llamado a la Casa Blanca para discutir con el entonces presidente Roosevelt la factibilidad de un sistema de autopistas a escala territorial. El presidente trazó sobre un mapa tres líneas que surcaban el suelo americano de este a oeste, y tres de norte a sur. El entonces naif y hasta torpe dibujo sería el puntapié para la redacción del estudio "Toll and Free Roads", que se convertiría en uno de los pilares fundamentales para el desarrollo del sistema.

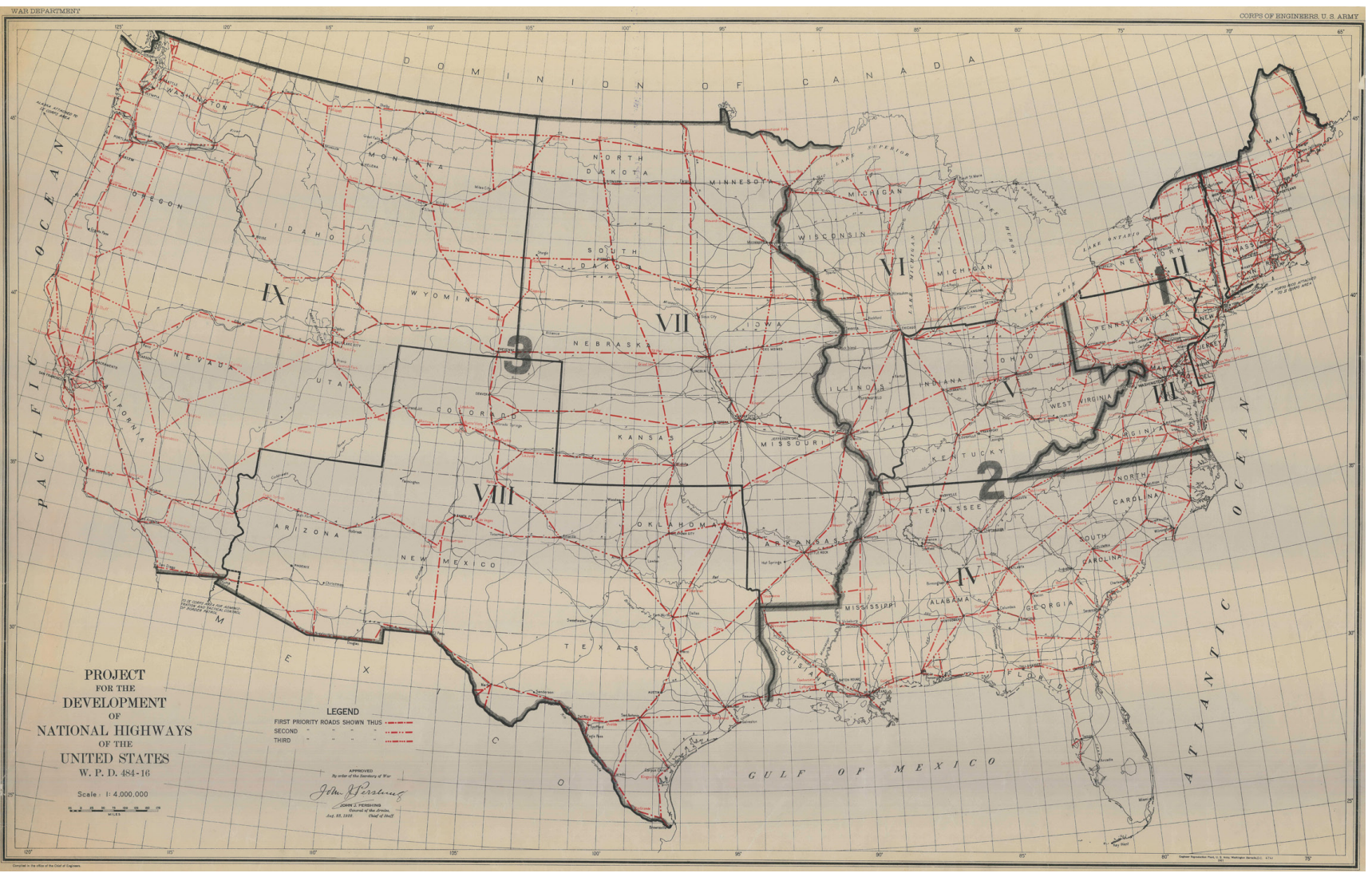

Mapa elaborado por el Departamento de Defensa y entregado por el Coronel John Pershing. "Pershing Map”. 1922. Cartographic and Architectural Records Section, Special Media Archives Services Division. Record Group 30. Records of the Bureau of Public Roads, 1892 - 1972. National Archives at College Park, College Park,MD. 


\subsubsection{Congestión y eficiencia}

En 1905, la esquina de Madison Street y State Street en Chicago, pasó a la historia como "The Busiest Corner in the World". Era la esquina más transitada del mundo, y en un tiempo de transición tecnológica, un auténtico catálogo de formas de transporte urbano. A medida que el automóvil se convertía en un objeto de uso masivo, y la población crecía con un consecuente aumento de la actividad económica, los centros de las ciudades comenzaron a sentir los efectos de un nuevo síntoma de la ciudad, la congestión. Como en el principio de acción y reacción de Newton, la ciudad sufre las mismas consecuencias del principio científico. Ante la congestión como implosión, surgiría la metrópolis como explosión de la misma energía. La eficiencia funcional era entonces un objetivo primordial para responder a los requerimientos de la nueva ciudad.

En 1908, se introdujo en la sociedad el Ford "T" o "Tin Lizzie". Henry Ford, su creador, estableció un método revolucionario; la línea de ensamblaje como forma de acelerar la producción y reducir los costos a niveles inimaginables. La producción en cadena ideada por Ford abrió las puertas al consumo masivo del automóvil. En breve, el vehículo se convierte en un certificado de libertad, sus dueños eran ahora dueños absolutos de la movilidad y a través de ello, y sin saberlo, capaces de establecer un nuevo patrón urbano.

En 1939 la General Motors promueve, en la Exposición Universal de Nueva York, "Futurama", una visión sobre el futuro del territorio. La exposición, ofrecía en una hora una visión radical de la ciudad y el territorio por venir, donde el coche había cambiado por completo el funcionamiento del tejido y la vida urbana, y en consecuencia, su fisonomía. Norman Bel Geddes, su diseñador, publica un año más tarde el libro "Magic Motorways" para exponer los principios teóricos de lo que había sido sólo una imagen.

La lista de referencias técnicas y teóricas que Geddes utilizó tanto para la exposición como el posterior libro poseen, en una abrumadora mayoría, un mismo trasfondo disciplinar: la ingeniería civil y la industria automotriz. Por un lado, la ingeniería aportaba una ciencia exacta de proyecciones y metodologías, resultado de la metamorfosis a través del tiempo de la calle tradicional y su desarrollo conceptual y tecnológico, y por otro la industria automotriz impulsaba toda iniciativa que contribuyera a popularizar el uso del automóvil como concepto 
asociado a la vida moderna² . Los organismos tomados como referencia por Geddes han sido caricaturizados como los villanos de la película, cuerpos poco sensibles o ignorantes de unas sacrosantas condiciones urbanas. Pero en esos años, las autopistas, y las autopistas urbanas, gozaban de una abrumadora popularidad: la red traería no más que beneficios

${ }^{2}$ La lista de organizaciones citada por Norman Bel Geddes como fuentes de información es extensa, pero entre ellos surgen los siguientes nombres: American Association of State Highways Officials, American Road Builders Association, Automobile Club of Southern California, Automobile Manufacturers Association, Institute of Traffic Engineers, Port of New York Authority, Public Road Administration, etc.

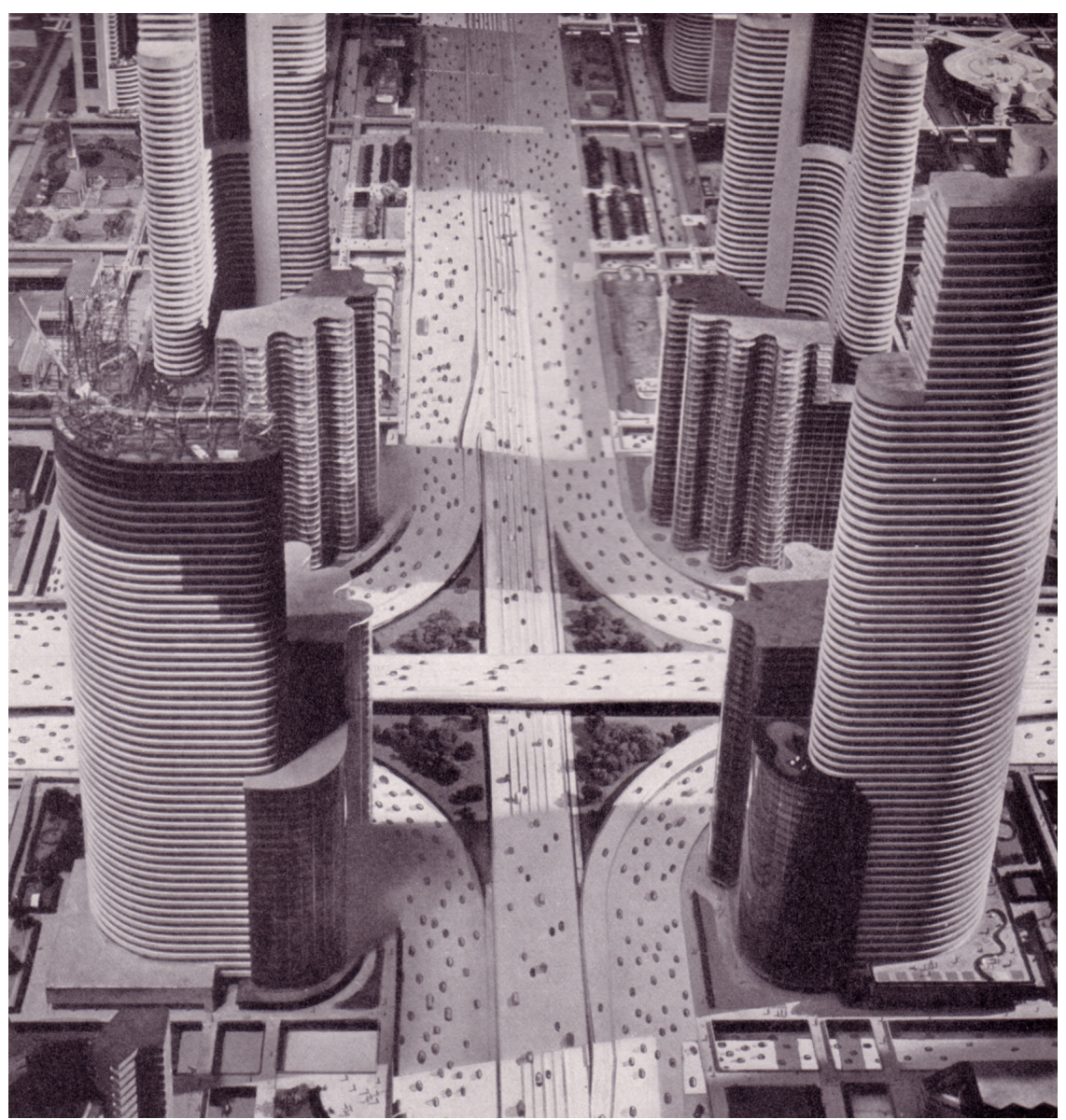

Imagen de Futurama. Magic Motorways. Norman Bel Geddes. 1940. 
Levittown. Kit de ensamblaje para una vivienda. 1947.

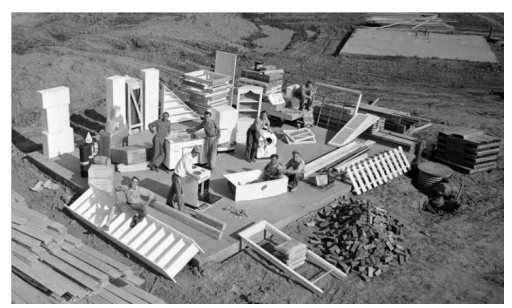

económicos, personales y sociales, y las ciudades eran las primeras beneficiadas.

La Regional Plan Association of New York, uno de los más poderosos organismos en relación al urbanismo en esos tiempos, era parte de la lista de Geddes, y en esos años cuando se comenzaba a debatir más detalladamente el sistema, aún como utopía, la asociación apoyaba su construcción como promesa de una ciudad y un territorio nuevos.

\subsubsection{El sueño americano y la autodependencia}

En los años treinta, la Federal Housing Administration establece un programa de préstamos para la construcción de viviendas unifamiliares en los suburbios. El programa era, fundamentalmente, una herramienta de activación económica ante la crisis financiera de esos años. Las hipotecas a escala masiva ofrecían la posibilidad de una casa propia en un entorno bucólico y alejada de la cada vez menos popular ciudad.

Al igual que la tecnología que había otorgado la posibilidad del automóvil, una producción en masa, esta vez de viviendas, comenzó a extenderse más allá de los conocidos bordes de las ciudades. La ciudad comenzó su mutación, convirtiéndose en un centro con actividades específicas, al que se le iban agregando apéndices habitados. En un corto tiempo, el automóvil se transformó en el componente fundamental de una nueva forma de vida, haciendo surgir un nuevo fenómeno: la autodependencia. El coche era ahora una herramienta de supervivencia territorial y su movimiento la demanda más acuciante. Pero la revolución creada por Ford no culminaba en la producción de vehículos. La cadena de producción probó ser altamente eficiente en la reducción de tiempo y costos, factores que podían, y lo fueron, ser aplicados en otros ámbitos.

Al terminar la segunda guerra la demanda por vivienda crecía. La oferta era escasa y los métodos tradicionales para satisfacer esa demanda eran demasiado lentos. William Levitt, de la constructora Levitt and Sons, decidió aplicar el invento de Henry Ford a la industria constructiva. La sistematización del proceso de ensamblaje era la respuesta perfecta a la demanda de vivienda asequible y al mismo tiempo un negocio extremadamente rentable. En 1947, a 25 millas de Manhattan, se construyó el primer "Levittown". "Island Trees", como era su nombre original, se transformó rápidamente en el nuevo ideal del sueño americano. 


\section{ID_INVESTIGACIONES}

William Levitt era el Henry Ford de la vivienda, y accidentalmente, un poderoso agente de planeamiento.

\subsection{Conciencia evolutiva}

Cuando las autopistas como los componentes de un sistema a nivel territorial comenzaron a proyectarse, tanto física como conceptualmente, se hicieron de manera de que pudieran ser eficientes en términos de capacidad y funcionamiento para responder a la demanda que las había originado, pero esa demanda no permanecería inmutable. Su complejidad aumentaba en torno a una trama de necesidades e intereses políticos, económicos, físicos y sociales. El proyecto de la autopista fue el resultado arduo de sucesivos documentos legales y "científicos" que iban modelando su forma y organizando su estructura institucional.

\subsubsection{Sistema: Toll and Free Roads}

En 1938 el entonces presidente Roosevelt encarga a MacDonald el primer estudio riguroso para la construcción de un sistema de interestatales. El mapa dibujado por Roosevelt en su reunión con el director del BPR, refleja la necesidad de establecer una estructura, tanto institucional como profesional, que pudiera coordinar y conducir un sistema de autopistas interestatales. El informe debía dar constancia de su viabilidad. Más que rutas de conexión entre puntos, ¿era posible un auténtico "sistema" de autopistas?

Hasta 1934, la ayuda federal para la construcción de unas muy primitivas autopistas estaba destinada a vías estrictamente rurales. La congestión creciente y la escasez de fondos o asistencia federales impulsó a los estados a gestar agencias de autopistas propias que desligadas del sistema federal, operaban en forma casi autónoma atendiendo a sus propias necesidades y operando desde sus propios fondos. Roosevelt, consciente de esta realidad, intentaría poner un orden federal y crear un sistema, una red de infraestructura basado en unos principios, funcionales, económicos y constructivos, comunes. El sistema como modelo de orden debía replicar el principio mismo del federalismo, un equilibrio entre una estructura centralizada para resguardar bienes comunes y una estructura autónoma atenta a asuntos específicos. 


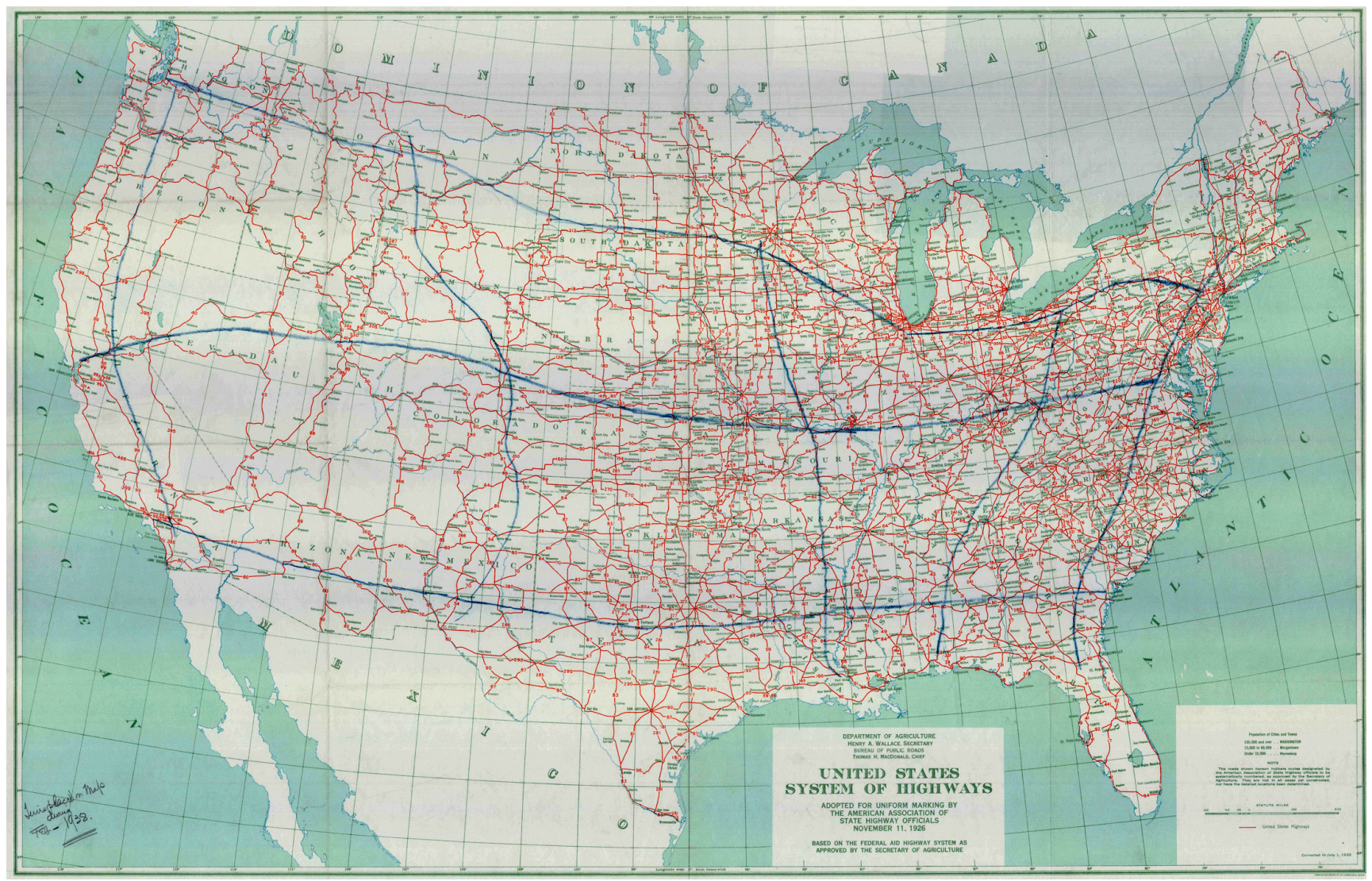

Mapa de las autopistas trazadas por Franklin D. Roosevelt en su reunión con Thomas MacDonald. 1938. Fuente: Cartographic and Architectural Records Section, Special Media Archives Services Division. Records of the Bureau of Public Roads, 1892-1972. National Archives at College Park,College Park,MD.
El informe tenía como objetivo estudiar la factibilidad de un sistema de autopistas de peaje y desde sus hallazgos elaborar un mapa tentativo de su organización territorial. Al finalizar el estudio, la conclusión era contundente: salvo en ciertas áreas de trafico abundante, que coincidían con las áreas urbanas más habitadas, era inviable el establecimiento de un sistema de autopistas de peaje como forma de autofinanciación. El sistema imaginado por Roosevelt demostraba ser un tanto diferente a la realidad palpable de esos años, tanto su financiación como su trazado debían reaccionar a los nuevos fenómenos de la movilidad.

Pero el informe excedió su objetivo original, ya no era tan sólo un estudio económico sino un 
primer estadio de las condiciones de diseño bajo las cuales las autopistas, como sistema, deberían construirse. El documento hacía una primera incursión en estándares de diseño como una anticipación de su futuro carácter morfológico. Para la escala que suponía la red era preciso una meticulosa definición de su constitución material a fin de garantizar la eficiencia funcional, pero también como medida de control para evitar caracterizaciones locales que entorpecieran su constitución como sistema.

Desde sus orígenes en 1890, el BPR había producido estándares de diseño desde su autoridad como organismo especializado, aunque su aplicación era opcional. Ante la creciente atención y demanda de un red de infraestructura, los estándares de diseño comenzaban a perfilarse como los auténticos protagonistas para la constitución de un sistema, su existencia y rigurosidad comenzaban a tomar el carácter de una ley, ligada a preservar el bien común. El BPR no sólo había cumplido con la tarea asignada por Roosevelt, establecer unos principios capaces de generar un sistema, sino que sentaba unas bases precisas sobre su capacidad profesional generando una posición dentro de la estructura institucional para su construcción. El sistema sólo se constituiría como tal si obedecía a un método preciso basado en principios de aplicación universal.

\subsubsection{Idealismo. Interregional Highway Report, 1943}

Ya entrados los años cuarenta, el éxodo de población hacia los extrarradios establecía una nueva presión sobre, el aún imaginado, sistema de autopistas: conectar los nuevos patrones urbanos con la ciudad central parecía ser su más ansiada promesa. Pero más allá de su capacidad funcional se apuntaba a que su existencia podía y debía ser un instrumento de organización espacial del suelo. Por primera vez se consideraba su capacidad como agente de planeamiento.

En 1941, el comité organizado por Roosevelt para la redacción de un nuevo informe contaba con la presencia de un amplio espectro profesional, el BPR, oficiales estatales de autopistas y tres reconocidos urbanistas: Harland Bartholomew, Frederic Delano y Rexford Tugwell. Las ciudades enfrentaban un período de cambios en su configuración física y para afrontar ese desafío, el diseño de las autopistas debía tener la lógica de una cadena profesional. 
En cada punto de intervención, expertos profesionales se harían cargo de su planificación asumiendo lo específico de su localización y jurisdicción.

En las ciudades, y en el pensamiento de quienes constituían el comité, era el momento para establecer un nuevo patrón de uso de suelos y el punto álgido para establecer las bases de su futuro desarrollo. Para el comité, consciente de la situación urbana de congestión de tráfico, la creciente decadencia del centro y la perdida del valor de la propiedad, el proyecto de las autopistas urbanas como parte del sistema era clave para la ciudad futura. El proyecto era viable, y su significado, idílico.

El 20 de diciembre de 1944, Roosevelt firmaba la Federal-Aid Highway Act, ley que sentaba sus principios en el Interregional Highway Report. En su gran mayoría, las recomendaciones incluidas en el informe sobre la necesidad de plantear de forma interprofesional e interestacalar la intervención de las autopistas en el interior de las ciudades, fueron eliminadas del texto final. En cuanto a las autopistas urbanas la ley autorizaba 40.000 millas, "...so located as to connect by routes, as direct as practicable, the metropolitan areas, cities and industrial centers..." (Interregional Highway Act, 1944) sin mayores consideraciones hacia su forma de implementación que la utilización de los estándares creados a tal objeto por AASHO, American Association of State Highways Officials y las rutas planeadas desde las agencias estatales despojando a cualquier otra agencia de planeamiento de un rol efectivo en el proyecto.

Lo que en un principio se imaginaba como una poderosa herramienta para el planeamiento urbano en el momento de máxima tensión y expectativa en la ciudad americana, se convirtió rápidamente en una herramienta de validación profesional para la ingeniería y un deterioro del valor de los profesionales del planeamiento urbano. Para los urbanistas, lo que comenzó como un prometedor instrumento de renovación urbana se convirtió en la revelación de una impotencia profesional. (Kemp, 1986)

\subsection{3 "Coast to Coast Without a Traffic Light”. Federal-Aid Highway Act. 1956.}

El 29 de junio de 1956, en el cuarto de un hospital y sin los protocolos habituales, un convaleciente presidente Dwight Eisenhower firmó la Federal-Aid Highway Act. El proyecto, 
llamado oficialmente "National System of Interstate and Defense Highways" sería la construcción más grande del mundo, el equivalente a sesenta veces el canal de Panamá. La firma cambiaría por completo la forma de vida y la configuración de la ciudad americana. Vivir en un lugar, trabajar en otro, salir a un tercero, y multiplicar las posibilidades al infinito gracias a la posibilidad del movimiento, esta vez definitivamente extendido a todo el territorio americano: "Coast to coast without a traffic light" ${ }^{3 .}$

Después de años de fallidos intentos en la implementación del sistema y de la descoordinada acción de los estados en la construcción de sus propias vías, Eisenhower había puesto el punto final: impulsar el sistema como "un" proyecto dentro un marco legal, institucional y económico. Dos factores eran los determinantes para su definitiva ejecución: el colapso total de los centros urbanos debidos al siempre creciente volumen de tráfico y la guerra fría, que volvía a poner sobre la mesa aquellas especulaciones de la "Transcontinental Motor Convoy". Los objetivos a alcanzar eran claros: eficiencia funcional, economía y rapidez.

En los doce años pasados de la ley firmada por Roosevelt, el BPR, AASHO y las agencias estatales de autopistas habían continuado su labor, profundizando en la definición de estándares y ajustándolos a los avances tecnológicos y mecánicos, y construyendo, cuando lograban reunirse los fondos, algunas autopistas de alcance estatal para responder a los problemas locales. La estructura institucional en la construcción de autopistas era ya un hecho consolidado, el BPR era un organismo de control, AASHO un organismo de especialización profesional y las agencias de autopistas un organismo de ejecución. La ley de 1956 estableció, fundamentalmente, una financiación federal que recuperaba el eslabón perdido, la conexión federal-estatal que garantizara unos principios de calidad y financiación comunes.

La ley de 1956 marcó el territorio, pero marcó además una clara delimitación de competencias profesionales. La empresa fue otorgada a las agencias federales y estatales de autopistas con casi nula ingerencia de las agencias de planificación o urbanismo, quienes de alguna forma, al menos en un comienzo, no pusieron mayor resistencia en asuntos que, a simple vista, no parecían ser específicos a sus competencias.

3 "Coast to Coast Without a Traffic Light" parece haber sido el slogan de la ley de 1956, pero a sido, hasta el momento imposible encontrar su fuente original. Libros, artículos y periódicos utilizan la frase para ilustrar los principios de la Federal-Aid Highway Act firmada por Eisenhower pero sin citar su procedencia. 


\section{BUENAS INTENCIONES}

En 1956, la tan esperada materialización de las imágenes que Futurama había construido en los años treinta se convertía, finalmente, en una realidad palpable. En plena euforia del sistema por venir, las autopistas se veían como el tan esperado remedio al enfermo cuerpo de la ciudad norteamericana. Sin embargo, mientras en los organismos públicos y en algunos ámbitos se veían como símbolos de progreso y eficiencia, una porción de la población urbana y ciertos círculos profesionales eran cada vez más sospechosos de sus bondades. El trasfondo histórico del sistema de interestatales, había producido, por razones concretas y otras veces a través de episodios aleatorios, el aislamiento de la autopista como objeto, tanto en su objetivo como en su diseño y su aterrizaje en áreas urbanas levantaba oleadas de descontento y desilusión. El idilio había acabado muy rápido, y a tan sólo un año de la ley de 1956, las voces de protesta se multiplicaban.

La creciente oposición desde diversos ámbitos se encarnó en una confrontación profesional: por un lado los ingenieros asignados para construir el sistema, quienes argumentaban contar con los instrumentos disciplinares adecuados y respaldados por una larga trayectoria ligada al proyecto, y por otro los urbanistas, quienes convertidos en populares abogados de unos valores urbanos supuestamente ignorados, buscaban reposicionar la profesión y su instrumental disciplinar en una empresa en la que habían quedado excluidos.

Las acusaciones entre ambos estaban dirigidas a sus respectivas capacidades - 0 incapacidades - profesionales para operar sobre una obra de infraestructura sin precedentes. Mientras los ingenieros eran señalados por poseer una visión reduccionista sobre el alcance de sus decisiones, los urbanistas eran acusados de no poseer un método preciso de actuación alternativa, valiéndose de generalizaciones impracticables que no se ajustaban a las demandas de la empresa en manos. La brecha estaba abierta, y en ella se discutían tres conceptos: capacidad profesional, rigurosidad disciplinar y jurisdicción de competencias.

La ciudad americana, e influenciada quizás por las dinámicas generadas en otros sectores como la producción en masa, se inclinaba en estos años, hacia una organización que respondiera en forma sistemática a dos factores: tiempo y economía. En los años 40 Harland Bartholomew había insistido ya en distanciar la disciplina del urbanismo del 


\section{ID_INVESTIGACIONES}

simple embellecimiento o estetización del entorno construido para enfocarse en el estudio del organismo urbano como un complejo funcional de relaciones sociales y económicas. Bartholomew, un agudo observador de los fenómenos urbanos, había presagiado que en el futuro las ciudades de su país establecerían su actividad y funcionamiento sobre esos factores.

Desde entonces, el urbanismo como disciplina se encontraba en un momento de fractura, el debate sobre sus objetivos, su identidad o falta de ella a través de claros cuerpos con poder institucional, el surgimiento de agentes de planeamiento que poco tenían que ver con la disciplina como tal, o su posición dentro de estructuras gubernamentales debilitaba su capacidad para proponer un contraste, o una alternativa, con las tareas asignadas y asumidas por los ingenieros. A diferencia de los urbanistas, sumidos en definir su identidad, los ingenieros habían logrado fortalecer su profesión ajustándose y respondiendo a las estructuras sociales y culturales de la idiosincrasia americana y del momento histórico. El problema de las autopistas no era tan sólo un problema ligado a su construcción material o su estructura política-ejecutiva, sino que era el reflejo, o la más concreta evidencia, de una crisis urbana en la que la ciudad americana intentaba redefinir su constitución tanto formal como organizativa.

En este efervescente contexto de posiciones encontradas una serie de conferencias surgen como un intento de conciliar posiciones o al menos reunirlas bajo un mismo ámbito. Tres conferencias marcan un momento de inflexión en el curso de los acontecimientos, estableciéndose como referente para una aproximación interdisciplinar o la definición específica de roles profesionales en distintos ámbitos. Las conferencias, son el registro de un tiempo convulso y de grandes cuestionamientos, y sus conclusiones un compendio de "buenas intenciones".

\subsection{The Hartford Conference. The New Highways: Challenge to the Metropolitan Region. 1957.}

"Expressways will determine the physical future of the metropolis. For this reason they cannot be considered merely as arteries of transport. They are the skeleton of tomorrow's 
city. The new highways afford the planner a potent tool for fashioning the kind of community that people want." (Owen, 1957)

El párrafo precedente pertenece al informe preparado por Wilfred Owen para establecer los principios guía del evento. La conferencia, promovida y organizada por la Connecticut General Life Insurance Company tenía como título "The New Highways: Challenge to the Metropolitan Region", aunque sería conocida simplemente como "Hartford Conference" por la ciudad en Connecticut donde fue celebrada.

Por años, y en parte a partir de la fuerte impresión popular causada por las poderosas imágenes divulgadas desde Futurama, la idea de una nueva ciudad delineada desde y sobre el potencial de las autopistas residía en el imaginario colectivo. La idea de que las autopistas eran el esqueleto de una nueva ciudad por venir implicaba una reestructuración de la lógica urbana que afectaba, al menos en su promesa, no sólo la movilidad, sino también una reorganización funcional, social y fundamentalmente, espacial.

Sin embargo, esta euforia surgida de potentes imágenes y un futuro moderno en su forma y prometedor en sus oportunidades había demostrado ser mucho menos elocuente y muy poco convincente en su traducción a la realidad. De la compleja ciudad mostrada por la General Motors en 1939 parecía quedar sólo un estructura de movilidad definida bajo términos científicos. La supuestamente simbiótica relación entre infraestructura y ciudad se había transformado en la superposición de un sistema con reglas propias sobre un ya problemático continuo urbano-suburbano.

El título mismo de la conferencia "The New Highways: Challenge to the Metropolitan Region" hacía referencia a la relación entre el área metropolitana como espacio físico y las nuevas autopistas como disparador de unas nuevas condiciones. La conferencia intentaba redefinir el rol de las autopistas en el contexto de su entorno territorial y operativo, y a raíz de ello, comprender las dinámicas o el impacto que produciría en su receptor físico. Este punto explica la razón por la cual la conferencia era organizada por una compañía de seguros. Más allá de su aparente filantropía, el interés de la empresa era dirigir la conversación sobre la construcción de las interestatales hacia su capacidad para establecer, modificar o eliminar valor al suelo urbano donde se desarrollaban sus negocios.

La conferencia exponía el colapso fortuito de un programa federal con una fortísima 
capacidad económica y de acción, con una mucho más débil, y a veces demasiado dispersa, estructura pública de construcción urbana. La explosión urbana que había generado el éxodo y la creación de suburbia era el resultado de una especulación económica a partir de la demanda por una mejor calidad de vida que los centros urbanos consolidados no eran capaces de brindar ante el crecimiento de la congestión y su incapacidad para reaccionar, tanto económica como institucionalmente, a las nuevas demandas de la vida moderna.

La lista de participantes es una vidriera de los abundantes y muy diversos intereses que la construcción del sistema había disparado, desde la necesidad de una validación profesional a intereses comerciales o hasta a veces unos bucólicos deseos de futuro, todos estaban incluidos con el fin de definir objetivos comunes.

Bertrand Tallamy, quien había sido nombrado en 1956 como Federal Highway Administrator y cuya función era la de servir como el más alto consejero del ejecutivo en materia de autopistas representaba no sólo la voz oficial, era la personificación de una forma de operar sobre el territorio urbano y el "acusado" en el juicio ficticio que representaba la conferencia. La exposición de Tallamy era corta y contundente, ligada a principios de rigurosidad metodológica y respaldada por números absolutos, su reclamo caía en la falta de respuesta de los organismos orientados a la producción urbana para producir políticas que, aprovechando el fuerte impacto económico que las autopistas producirían en la ciudad, fueran capaces de absorber y transformar todos esos tóxicos efectos de los que eran acusadas. Tallamy dejaba al descubierto una pregunta fundamental: ¿Era realmente la autopista la culpable de todos los males, o era la misma ciudad incapaz de adaptarse a los cambios que se generaban en ella? Sutilmente, esta pregunta desplazaba la responsabilidad de las supuestas atrocidades construidas o a construirse hacia un vacío institucional y profesional que tomara a la ciudad, compleja y cambiante, como el centro de sus debates.

Lewis Mumford ha sido siempre retratado como un feroz enemigo de las autopistas urbanas, pero su conferencia, Ilamada a cerrar el evento es más ambicioso, y al mismo tiempo naif, de lo que muchas veces se ha retratado a través de un célebre pero muy pequeño segmento de su exposición: "..we Americans have an almost automatic inclination to favor anything that seems to give added attraction to the second mistress that exists in every household right alongside the wife-the motor car." (The New Highways: Challenge to the Metropolitan Region, 1957) 
La presentación de Mumford podría resumirse en tres puntos, por un lado un impiadoso ataque a la sociedad americana y su creciente incapacidad para priorizar los beneficios colectivos sobre los individuales. Para Mumford, la euforia del vehículo propio, la libertad otorgada por la máquina y una estereotipada imagen de la vida moderna había impulsado un programa perverso, sus fines eran al mismo tiempo el mal a evitar y el máximo goce.

El segundo punto de la exposición de Mumford refiere a una declaración de obsolescencia de la ciudad como era conocida. Como otros miembros de la conferencia, desmitifica el centro como única conjunción geográfica, administrativa y cultural eliminando así la casi incuestionable necesidad de extender el sistema de autopistas hacia el corazón de la ciudad, y reconociendo además el valor de un surgimiento de nuevos centros que debían formar parte de una nueva tipología urbana: la ciudad regional. El modelo planteado por Mumford tenía fuertes raíces en la Regional Planning Association of America y representaba un final en la dependencia creada por el modelo geométrico de centro y periferia, que sería reemplazado por un modelo de células independientes.

Para Mumford la conferencia era una oportunidad para revitalizar y extender los conceptos de la ciudad regional en el contexto americano, mientras en Inglaterra estas ideas eran ya aplicadas en políticas de planeamiento ${ }^{4}$. Si bien la noción de la ciudad regional había sido gestada en el contexto americano la razón para que fueran aplicadas en Europa residía en dos factores, el primero una política de planeamiento centralizada en la forma de un organismo con capacidades ejecutivas y, paralelamente, un poder privado con menos capacidad de influencia sobre las decisiones políticas ligadas al territorio.

Mumford, como muchos representantes del planeamiento, abogaba por la creación de organismos que tuviesen capacidad de coordinación entre políticas de naturaleza diversa a través de sus instrumentos profesionales. El establecimiento de estos cuerpos elevaría la capacidad del planeamiento a un estatus más institucional y con capacidad ejecutiva. Para ello, y como su tercer punto, insta al reestablecimiento de un organismo abolido en 1939 el National Resources Planning Committee. No es casual que Mumford invocara este cuerpo creado por Roosevelt en 1935. El objetivo del comité era el de actuar como consejero

${ }^{4}$ Peter Hall, en su libro Cities of Tomorrow y en capítulo dedicado a "The City and the Region" realiza un exquisito análisis sobre las circunstancias en torno a la ciudad regional en el entorno americano en contraposición al europeo tanto en su concepción teórica como en su aplicación práctica. 
gubernamental y enlace entre diversas agencias; el origen diverso de sus miembros era al mismo tiempo una señal de lo inclusivo de su visión y una herramienta de control para no potenciar intereses de algunas agencias sobre otras evitando el monopolio. Mumford, materializaba así el que había sido el reclamo de muchas de las ponencias anteriores: el exigir la creación un organismo capaz de regular el uso del suelo a escala inter-jurisdiccional, reciclando uno de los más interdisciplinares organismos creados desde el gobierno.

Pero ese no era el único organismo que se reclamaba. Si el National Resources Planning Committee funcionaría como organismo de control y vinculación entre jurisdicciones, los "Port Authorities" serían organismos con una alta capacidad operativa para intervenir sobre tres agentes de formación territorial: infraestructuras, suelos y distribución de población. La creación conjunta de ambos organismos era una embestida, y un intento por restar poder, a los cuerpos que, responsables por la construcción del sistema interestatal, parecían contar con casi un poder absoluto en la trasformación del territorio.

Al cierre de la conferencia, los ingenieros y las organizaciones ligadas al sistema de interestatales fueron catalogados como personajes impiadosos con una alta, y peligrosa, dosis de poder. El villano enemigo de la ciudad había sido, sin dificultades, retratado.

Mumford y otros conferenciantes solicitaron entonces un aplazamiento temporal del programa de interestatales a fin de organizar un estudio comprensivo de la realidad urbana como base para planear el futuro. El pedido fue rechazado desde el gobierno, aduciendo plazos temporales que no podían ignorarse y que traerían consigo respuestas a muchos de los reclamos que en ese momento más que doradas oportunidades se veían como flagrantes desastres.

El pedido de Mumford y otros tantos por un aplazamiento temporal del programa dejaba en evidencia la falta de un estudio que debería haberse llevado a cabo años atrás, cuando los fenómenos que dieron lugar al sistema de interestatales comenzaron a surgir. Los organismos ligados a la construcción de autopistas nutrieron por años un arsenal disciplinar al ritmo de la historia, los adelantos técnicos, los avances socio-económicos y la mutación de las estructuras gubernamentales fueron parte de sus especulaciones para solidificar una especialización profesional y una posición ejecutiva. El urbanismo, en cambio, había quedado varado en una generalización profesional que hacía, en un contexto de 
"More than half of the nation's motor vehicles are now massed on urban streets. To eliminate major traffic bottlenecks and help make cities more livable are important considerations in locating new urban highways." The Sagamore Conference on Highways and Urban Development. Guidelines for Action. Publicación original. 1958 multiplicación de fenómenos y complejidad de factores, sus capacidades innecesarias y casi obsoletas. Las bellas imágenes de ciudades bucólicas y armónicas con todos sus componentes habían distraído a el urbanista de la ciudad real, una que era ya imposible de abarcar bajo el sueño de una utopía.

\subsection{The Sagamore Conference. First National Conference on Highways and Urban Development. 1958}

Luego de la mala publicidad que había recibido la implementación de la ley de 1956 al finalizar la Hartford Conference debido a las múltiples objeciones que surgieron de ella, el 5 de Octubre de 1958, en la Universidad de Syracuse, se congregó la "First National Congress on Highways and Urban Development". El evento, subvencionado por la Automotive Safety Foundation estaba patrocinado por el Highway Research Board (HRB) y un comité en autopistas formado por la American Municipal Association (AMA) y la American Association of State Highway Officials (AASHO).

La conferencia en Hartford había producido un fuerte impacto en la opinión popular, el

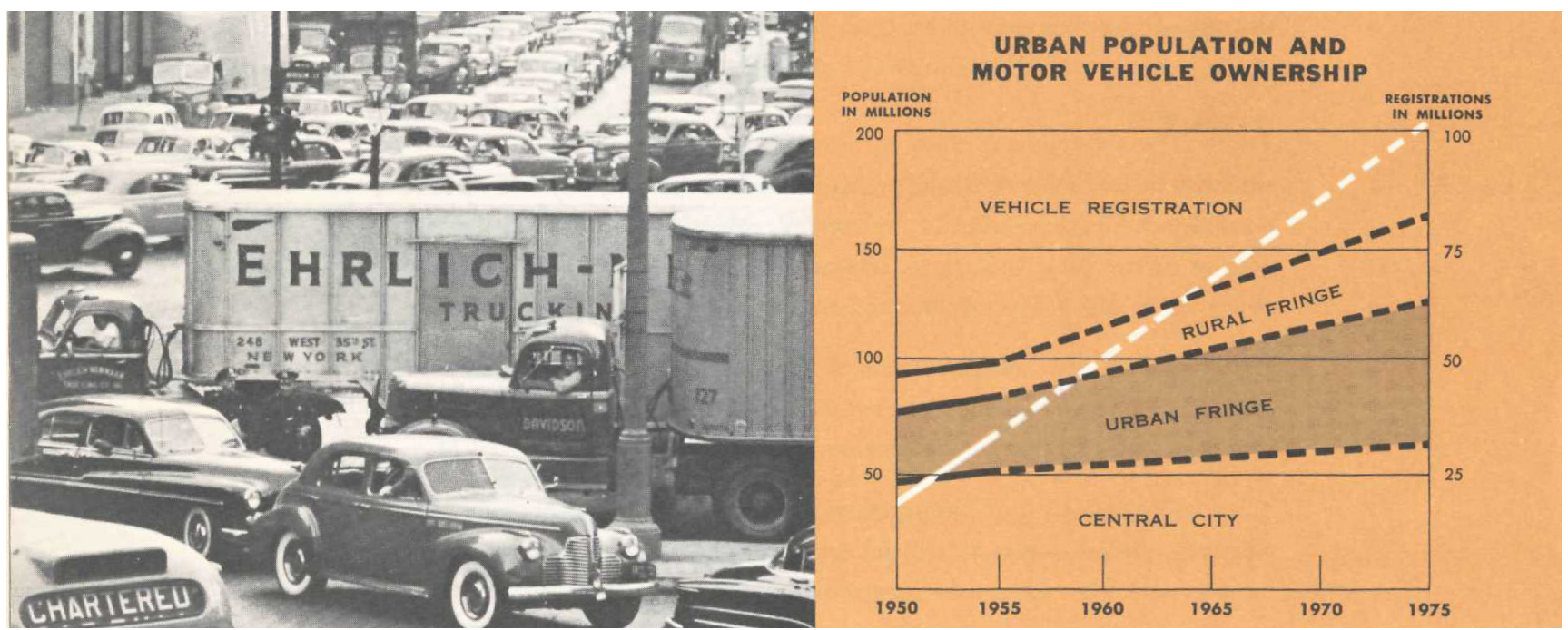


malestar hacia los organismos a cargo de las interestatales sólo iba en aumento como también la desconfianza hacia los objetivos del programa federal y sus muy prometidos beneficios. La falta de cooperación entre organismos municipales, estatales y federales, la desconexión entre programas de financiación federal de intervención en los tejidos urbanos, la escasa injerencia de organismos ligados al planeamiento, y sus correspondientes consecuencias eran los tres pilares de la crítica que construía a pasos agigantados una fuerte oposición a la construcción del sistema.

El tono de la conferencia resulta completamente diferente a aquel otro, bastante crítico, lleno de denuncias y proyectos posibles, que dominó la Hartford Conference. De tono conciliatorio y a favor, al menos en teoría, de la colaboración interjurisdiccional e interprofesional, la conferencia parecía ser el inicio de una era de consenso y relaciones fluidas entre distintos actores políticos y profesionales. Sin embargo, esta armonía no era fruto de un repentino y amigable acercamiento entre posiciones opuestas, sino en que era el resultado de una intencionada selección de asistentes. A tan sólo un año de la conferencia que había producido una estampida de opinión pública, la nueva conferencia abogaba por evitar conflictos y guiar sus objetivos hacia fines prácticos a través de una selecta lista de invitados para acuñar acuerdos. Era un momento crítico en la construcción del sistema, y para avanzar en el progreso de los ya muchos planes elaborados, o aquellas otros que estaban ya en ejecución, era necesario construir al menos la sensación de un acuerdo promoviendo objetivos comunes para recuperar la aprobación pública.

La falta de coordinación o colaboración con organismos de escala local que se indicaba como el gran ausente se debía, en muchos casos, a la conjunción del acelerado proceso de implementación del sistema desatado por la repentina y caudalosa disponibilidad financiera y que aquellos planes, regionales, metropolitanos, o urbanos que tanto se reclamaban en la crítica como parte imprescindible en la ecuación de la radical transformación de las ciudades en ese momento eran, en casi la totalidad de los casos, quimeras imaginadas o débiles planes de a veces escuálidas oficinas de planeamiento.

Hemos notado ya la disputa entre la ingeniería y el planeamiento por la capacidad o incapacidad de sus instrumentos disciplinares. Ingenuamente, con buenas o dudosas intenciones, la conferencia indaga sobre unos posibles instrumentos de actuación. El uso de la metodología científica, basada en rigurosas fórmulas de recolección de datos 
y estandarización de los mismos, y notablemente cercana a la utilizada por la ingeniería, se proponía como respuesta a la tan requerida reorganización operativa y ejecutiva en la construcción del sistema, esta vez aplicada al territorio. Más allá de la crisis inmediata originada por las autopistas en los entornos urbanos, la crisis real se hallaba en la falta de una metodología clara que sistematizara las necesidades o potencialidades de los ámbitos urbanos y que retroalimentara la tan rigurosa constitución del sistema de interestatales.

El documento, en diversas oportunidades, ofrece una solución a esta necesidad a partir de extender los métodos utilizados desde la ingeniería, como aplicables a otros ámbitos. En el apartado dedicado a "Financing and Planning Urban Highways Needs" el lenguaje y las recomendaciones para llevar a cabo la tarea son una clara alusión a estos métodos, idea que se ve reforzada ante el complejo ensamblaje de agencias en las que sólo una estructura de rigor científico podría navegar intereses de tan diversa naturaleza. En consecuencia, se proponen, entre otros, medidas como las de unos "Basic Standards" o la necesidad de unos "Adequate Facts" como medidas esenciales que deberían guiar las tareas de estas colaboraciones.

Esta rigurosa aproximación a partir de datos cuantitativos se vuelve mucho más difusa cuando se mencionan asuntos que, aún ligados al planeamiento de la ciudad y a una posible coordinación entre políticas federales, no parecen encajar en los encorsetados y limitados objetivos reales del documento, que apuntaba fundamentalmente a definir una protección o salvaguarda del sistema de las interestatales sin modificar sustancialmente su estructura organizativa. Así sucede cuando se menciona la tan discutida idea de un planeamiento regional, reduciendo sus recomendaciones en unas escuetas palabras sin mayor contenido que el de la obligación de ser nombrado en el documento por la repercusión pública que había recibido. El evento cuya naturaleza era la de coordinar políticas de escala urbana y territorial para potencializar sus beneficios en pos de un proyecto conjunto, dejaba lo que parecía ser un punto clave como un asunto relegado a una cuestión de sentido común, de necesaria existencia. El no pronunciarse detalladamente sobre este tema delataba una vez más que aunque lo objetivos iniciales de la conferencia eran comprensivos y extensos en cuanto a sus intenciones, el foco de discusión estaba ligado a reforzar la construcción del sistema, atendiendo sólo en apariencia o pretendiendo atender, lo que su título prometía "Highways and Urban Development". 
Luego de cinco días de supuesto debate, la conclusión de la conferencia era en realidad la misma razón que le dio origen. "Five days of intensive Conference discussions produced conclusive evidence that highway transportation and other elements of urban development are inseparable...". Más tarde, la realidad demostraría que más allá de las buenas intenciones contenidas en la conferencia, la maquinaria institucional y profesional, y las prioridades establecidas por el programa de las interestatales no se vería afectada en absoluto por los ambiciosos objetivos del evento, permaneciendo inalterable y operando tal y como lo había hecho hasta ese momento. (Rose, 1990)

\subsection{The Hershey Conference. Freeways in the Urban Setting. 1962}

A diferencia de sus predecesoras la tercera conferencia, llamada "Hershey Conference" de 1962 tenía como eje de discusión un objetivo preciso y limitado: las autopistas en el entorno urbano. La conferencia en Hershey era la antesala de la política del llamado "3C Planning Process" incluido en la Federal-Aid Highway Act firmada por John F. Kennedy unos pocos meses después. La ley establecía un proceso de planeamiento para las autopistas urbanas sobre tres principios "cooperative, comprehensive, and continuing planning", lo que implicaba, bajo la fuerza de una ley, una nueva oportunidad para redefinir los roles profesionales y reestructurar el sistema burocrático-institucional de las interestatales.

"Much still remains to be done, but the concept that urban highways systems should be planned in conjunction with comprehensive community planning is now generally and widely
Los participantes de la Conferencia. Entre ellos, a la izquierda, Donald Appleyard, quien investigaba junto a Kevin Lynch y John Myer en el Massachussets Institute of Technology (MIT) en Cambridge las capacidades estéticas de las autopistas urbanas y su potencial uso como herramienta de diseño.

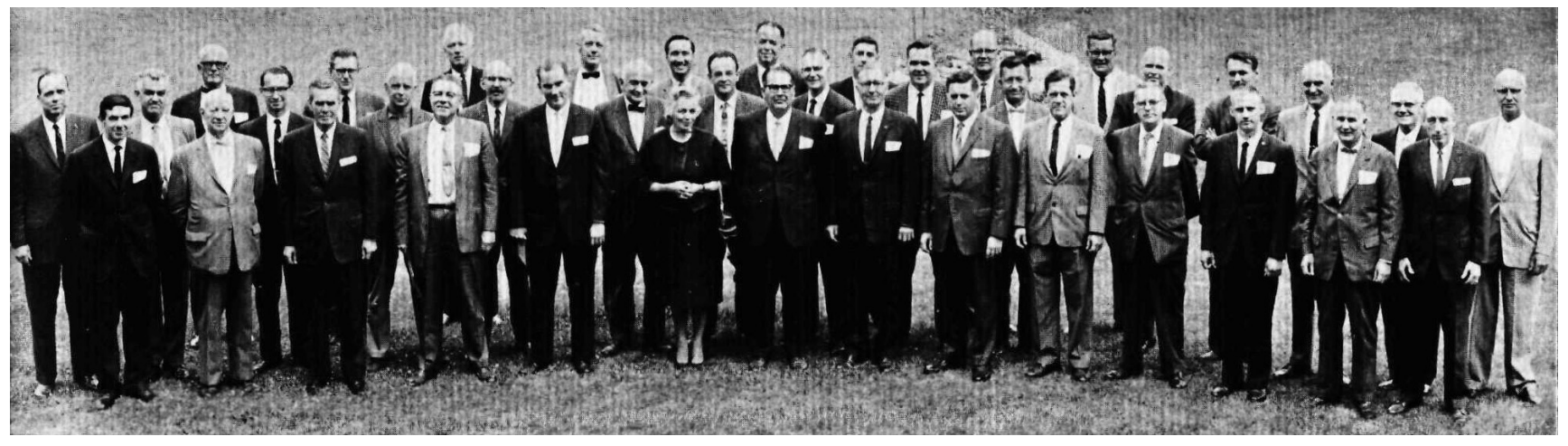


accepted" (Freeways in the Urban Setting, 1962). La conferencia en Hershey cerraba un ciclo. El sistema de interestatales no podía ser planeado en forma independiente. La colaboración entre escalas y jurisdicciones era no sólo necesaria, sino fundamental para garantizar su continuación.

En su prólogo, el documento de la conferencia enumera las incompatibilidades entre visiones que habían impedido, hasta ahora, una visión comprensiva que abarcara la ciudad y el sistema de interestatales. La diversidad de agencias, y sus propias estructuras institucionales eran una parte del problema, pero el énfasis residía en los conflictos que aparecían cuando se trataba del diseño y la ubicación de las autopistas en los senos urbanos. La conferencia, o sus conclusiones debían dar respuesta a tres factores: el futuro uso del suelo, unos valores estéticos y las demandas del tráfico.

El documento se estructura en dos partes, una referida a unas conclusiones, fruto del estudio de la realidad reinante y de las conclusiones arrojadas por años de leyes y conferencias, y una segunda que hacía hincapié en unas recomendaciones. La primera parte es un canto de esperanza, ideas como las de un "total design concept" (Freeways in the Urban Setting, 1962) o la aserción de que la mera aplicación de estándares no sería suficiente para alcanzar los nuevos objetivos, poblaban los siete puntos en los que se resumen las conclusiones.

Las recomendaciones, en cambio, se postulan como un espacio para otorgar y reconocer responsabilidades y la primera es clara: las ciudades y sus agencias de planeamiento debían aceptar la responsabilidad de acelerar el planeamiento urbano como un prerrequisito para el desarrollo del sistema de autopistas. Ahora bien, el sistema de interestatales poseía una estructura institucional sólida, y muy consolidada en sus funciones. ¿Tenía la ciudad un equivalente para equiparar, en experiencia, especialización y financiamiento a sus posibles socios?

Los nueve puntos reunidos en las recomendaciones giran en torno a la necesidad de una comprensión más profunda de los factores involucrados en el diseño conjunto de la ciudad y la autopista, en lugar de la ciudad en la autopista. Esta sutil diferencia de palabras no es un dato menor, ya que la autopista como objeto aislado había sido el foco de las acusaciones por años. La conferencia en Hershey significa un cambio rotundo en la observación de los fenómenos urbanos surgidos, materializados o no, desde principios de siglo. Las ciudades, 


\section{ID_INVESTIGACIONES}

más allá de las modernísimas autopistas que eran ahora parte de su fisonomía, eran organismos totalmente diferentes a los contenidos por antiguas normas, planes o conceptos urbanos. Ese cambio, producido a una velocidad sin precedentes, no había dejado espacio para la adecuación de sus estructuras, ni espaciales, ni formales, ni institucionales. La realidad de la ciudad era una que debía aún ser descubierta y el urbanismo debía comprender sus demandas para recuperar su lugar.

\section{CONCLUSIONES}

Las conferencias aquí descriptas actuaron no tanto como un modificador directo de la realidad sino como la evidencia de una crisis profesional e institucional sin precedentes. La ciudad era de repente construida por agentes de planeamiento que, con poderosas herramientas disciplinares y económicas volvían obsoletas los instrumentos del urbanismo tradicional.

Se ha redactado ya esta historia desde la caricatura de un ring donde enfurecidos urbanistas levantan sus guantes ante la mirada relajada de ingenieros que sabían que la lucha estaba ganada antes de empezar. Pero esta imagen, aunque efectiva, es reduccionista. El sistema de interestatales no fue el resultado de una decisión deliberada por despojar a los autores de la ciudad de sus herramientas. El siglo XX ha sido el escenario de un tiempo acelerado, que ha cambiado estructuras a una velocidad que requería estar atento para entender las nuevas dinámicas y adaptarse a ellas.

Volviendo a la más simple dicotomía de ingenieros y urbanistas, los primeros supieron ver el impulso de los fenómenos, tan americanos entonces, de la movilidad, la redistribución poblacional y las nuevas estrategias de guerra como potenciales factores para el desarrollo de su disciplina. En el ámbito americano, donde las estructuras gubernamentales están siempre a la sombra de la sospecha de concentrar demasiado poder y por ello volverse antidemocráticas, la especialización profesional ligada a la implementación de una política pública era señal de haber comprendido el medio y el momento histórico en el que se estaba operando.

Por otro lado, los urbanistas, fracasaron a nuestro juicio, en comprender el valor de la 
especialización sobre la generalización como instrumento para infiltrar un momento histórico que requería de métodos más que visiones. Lejos de renunciar a sus utopías, los urbanistas se refugiaron en los dos únicos lugares en los que eran escuchados, la academia como espacio para tejer utopías y el grito de denuncia para dejar de manifiesto su desacuerdo con la realidad. Ninguno de ellos pudo competir con la rotunda realidad de un método y la contundencia de una estructura institucional nutrida por años.

Las conferencias dejaron en evidencia la ausencia de una clara definición instrumental y metodológica del urbanismo como disciplina ante la llegada de una nueva escala y un tiempo acelerado. El debate había sido perdido mucho antes de que se encendieran los micrófonos. 


\section{ID_INVESTIGACIONES}

\section{BIBLIOGRAFÍA}

Conferencias y documentos oficiales

The new highways: challenge to the metropolitan region. (1957). General Life Insurance Company. Hartford, Connecticut.

OWEN, Wilfred. The New Highways: Challenge to the Metropolitan Region. (1957). General Life Insurance Company. Hartford, Connecticut.

Proceedings of the National Conference on Highways and Urban Development. (1958). American Municipal Association. Syracuse University. New York.

Freeways in the Urban Setting: the Hershey Conference. (1962). Automotive Safety Foundation. Washington, D.C..

A Book About Space. (1968) U.S. Department of Transportation/ Federal Highway Administration/ Bureau of Public Roads. Washington, D.C..

Obras completas

EASTERLING, K. (1999). Organization Space. Landscapes, Highways and Houses in America. Cambridge, Massachusetts: The MIT Press,.

HALL, P. (2002). Cities of Tomorrow. An intellectual History of Urban Planning and Design in the Twentieth Century. Oxford: Blackwell Publishings.

LEVITT, H. (1970). Superhighway-Superhoax. New York: Doubleday \& Company Inc..

MUMFORD, L. (1989). The City in History. Its Origins, Its Transformations and Its Prospects. San DiegoNew York-London: A Harvest Book, Harcourt Brace \& Company.

MUMFORD, L. (1956). The Highway and the City. New York: A Harvest Book, Harcourt Brace \& Company. PATTON, P. (1986). Open Road. A Celebration of the American Highway. New York: Published by Simon and Schuster.

ROSE, M. (1990). Interstate: Express Highways Politics 1939-1989. Knoxville: The University of Tennessee Press. 
SIES, M. C. and SILVER, C., Editores. (1996) Planning the Twentieth-Century American City. Baltimore and London: The John Hopkins University Press.

SWIFT, E. (2011). Big Roads. The Untold Story of the Engineers, Visionaries and Trailblazers Who Created the American Superhighways. Boston and New York: Houghton Mifflin Harcourt.

\section{Revistas}

KEMP, L. W. (1986). Aesthetes and Engineers: The Occupational Ideology of Highway Design. Technology and Culture. Vol. 27, № 4, Special Issue: Engineering in the Twentieth Century, pp. 759-797. 
